6 Powell, H, et al, Fournal of Pediatrics, 1973, 82, 976

7 Shuman, R M, Leech, R W, and Alvord, E C, Pediatrics, 1974, 54, 689.

${ }^{8}$ Vaterlaus, B P, and Hostynek, J J, fournal of the Society of Cosmetic Chemists, 1973, 24, 291.

- Lockhart, J, and Simmons, H E, Pediatrics, 1973, 51, no 2 pt 11, 430.

10 Plueckhahn, V D, and Banks, J, Medical fournal of Australia, 1972, 1, 897.

11 Light, I J, and Sutherland, J M, Pediatrics, 1973, 51, no 2 pt 11, 345.

12 Shuman, R M, Leech, R W, and Alvord, E C, Archives of Neurology, 1975, 32, 320.

13 Plueckhahn, V D, and Collins, R B, Medical fournal of Australia, 1976, $1,815$.

14 Towfighi, J, Gonatas, N K, and McCree, L, Laboratory Investigation, 1974, 31, 712 .

15 Udall, V, and Malone, J C, Proceedings of the European Society for Study of Drug Toxicity, 1970, 11, 233.

${ }^{16}$ Kimbrough, R D, and Gaines, T B, Archives of Environmental Health, $1971,23,114$.

17 Plueckhahn, V D, Medical fournal of Australia, 1973, 1, 93.

18 Alder, V D, et al, Lancet, 1972, 2, 384.

19 Mullick, F G, Pediatrics, 1973, 51, 395.

${ }^{20}$ Cunningham, M D, and Tsoulos, N G, Pediatric Research, 1972, 6, 431.

\section{Diabetic feet}

Lesions of the feet in middle-aged and elderly diabetics are usually caused by the combined effects of sepsis, neuropathy, and ischaemia. Before treatment, every patient must be assessed to decide the relative importance of these factors. In the absence of severe ischaemia conservative medical and surgical management may produce spectacular results.

Diabetic neuropathy affects both the somatic and the autonomic nerves in the feet. The patient often complains of paraesthesiae, and diminished sensation and absent ankle jerks are found on physical examination. Weakness of the small muscles of the foot leaves the pull of the long muscles of the toes unopposed, producing crumpling and clawing, especially of the 3rd, 4th, and 5th toes. Weight distribution in the foot is disturbed, which leads to excessive pressure on a small area; and because of the diminished sensation the patient may be unaware of any skin damage. Callosities develop and may progress to penetrating ulcers, and healing may be impaired because local vascular reflexes are disturbed by autonomic neuropathy. Osteomyelitis of the metatarsal heads and phalanges is common, and gross cellulitis of the whole foot and infective gangrene may result. The foot is hot, red, and swollen and the pulses are usually bounding. Unfortunately, the condition is often well advanced before the patient seeks advice.

Pure ischaemia in the diabetic patient is 'no different from that seen in the non-diabetic individual. Absent pedal pulses associated with coldness, persistent colour change, rest pain, and the presence of dry gangrene are sinister symptoms. Unless the limb can be salvaged by direct arterial surgery a major amputation is usually necessary.

A comprehensive retrospective analysis of the records of 172 diabetic patients who had had operations on their feet has recently been published from the USA. ${ }^{1}$ The important finding was that operations carried out in the presence of severe active infection-high fever, leucocytosis, high blood sugar, and subcutaneous gas on the radiograph-gave poor results. This conclusion confirms the orthodox British teaching that rest, raising of the limb, and antibiotics may often transform a clinical picture that seemed a lost cause. ${ }^{2}$ Urgent surgical drainage of a fluctuant abscess may be required, but other surgery should be delayed until the maximum benefit has been obtained from conservative treatment. Great care must be taken to prevent the development of pressure sores on the heels of both the good and the bad leg, and the use of padded canvas slings has been recommended. ${ }^{2}$ Bone lesions may not show on the radiograph for two to three weeks, so conservative treatment also allows the physician to make a more precise assessment of the extent of the osteomyelitis. Once the cellulitis has been controlled then debridement is required to remove infected bone. Surgical technique is important: no tourniquet should be used and the wounds should not be sutured, a technique which prevents any dead space forming and so lessens the opportunity for infection to persist. Furthermore, any postoperative swelling of the wound does not imperil the viability of the skin edges. Simple neuropathic lesions usually heal without operation provided that attention is given to detail in the conservative treatment and that both the doctor and the patient are prepared to wait.

Every diabetic patient should be taught the importance of foot hygiene, sensible footwear, and regular chiropody. For the elderly this will usually mean the services of a chiropodist. The use of orthopaedic footwear to minimise the pressure effects produced by the foot deformities is also important in helping to prevent the development of these lesions. Prevention is better than cure.

1 Goodman, J, et al, Surgery, Gynecology and Obstetrics, 1976, 143, 587.

2 Catterall, R C F, in Clinical Diabetes, eds W G Oakley, D A Pyke, and K W Taylor. Oxford, Blackwell, 1968.

\section{Asymptomatic proteinuria in the preschool child}

What is the significance of detection of proteinuria at a routine preschool clinic or as a chance finding when a child has come to the surgery or health centre for an unrelated reason? What course of action should be taken to exclude serious renal disease? These questions must face doctors frequently, yet the answers are far from clear-cut. The association between proteinuria and almost all types of nephropathy has been well recognised for many years, even though in severe obstructive nephropathy or chronic pyelonephritis protein may be absent from the urine. Urinary screening of school children has shown, however, that, though asymptomatic proteinuria and bacteriuria are both common, especially in adolescent girls, their correlation is poor. ${ }^{1}$ Proteinuria is not a good indicator of urinary tract infections.

Normally between 50 and $150 \mathrm{mg}$ of protein is excreted in the urine in 24 hours. The amount in a single specimen varies with the output, the concentrating ability, and the time of day. Chemically impregnated dipsticks are sensitive to $10-20 \mathrm{mg} / \mathrm{dl}$, so from time to time the test is likely to detect physiological amounts as a "trace." If the reading is $+(30 \mathrm{mg} / \mathrm{dl})$ this may represent clinically significant proteinuria. Even so, false-positives are frequent-for example, in alkaline specimens-and the presence of proteinuria must be confirmed by the salicylsulphonic acid test. This is simply performed by adding $0.5 \mathrm{ml}$ of $3 \%$ SSA to an equal volume of urine and observing turbidity. Quantitation is possible using a spectrophotometer and a standardised curve.

Once proteinuria has been confirmed a detailed history and examination are needed either to establish a simple explanation or to exclude obvious renal causes. Transient proteinuria may follow exercise, emotional stress, exposure to cold, or fever of 